\title{
Paris saponin VII suppressed the growth of human cervical cancer Hela cells
}

\author{
Wenjie Zhang ${ }^{1+}$, Dian Zhang ${ }^{2 *}, \mathrm{Xi} \mathrm{Ma}^{1}$, Zhaoyang Liu' ${ }^{1}$, Fang $\mathrm{Li}^{1}$ and Dongna Wu${ }^{1}$
}

\begin{abstract}
Background: Saponins of several herbs are known to induce apoptosis in many cancer cells. The present study aimed to investigate the growth inhibitory effect of Paris saponin VII (PS VII), a kind of steroidal saponins from Chonglou (Rhizoma Paridis Chonglou), on the human cervical cancer cell line Hela and the relative molecular mechanisms.
\end{abstract}

Methods: Hela cells were exposed to different concentrations of PS VII (1 to $100 \mu \mathrm{M})$. Inhibition of cell proliferation was measured by 3-(4,5-dimethylthiazol-2-yl)-2,5-diphenyltetrazolium bromide (MTT) and 5-ethynyl-2'-deoxyuridine (EdU) assays. The amount of apoptotic cells was evaluated by flow cytometric analysis. And the protein level of cleaved caspase-3, cleaved caspase-9, Bax, and Bcl-2 was evaluated by Western blot.

Results: The half maximal inhibitory concentration $\left(I C_{50}\right)$ value of PS VII for the growth inhibition of Hela cells was $2.62 \pm 0.11 \mu \mathrm{M}$. PS VII increased the expression of caspase-3, caspase-9, and Bax while decreased that of BCl-2, suggesting that PS VII may induce apoptosis through intrinsic apoptotic ways.

Conclusions: These data indicate that PS VII has the potential for the treatment of cervical cancer.

Keywords: Paris saponin VII (PS VII), Cervical cancer, Proliferation, Apoptosis

\section{Background}

Cervical cancer is the third most common type of cancer in women worldwide, and a leading cause of cancer-related mortality, with an estimated 275,000 deaths in 2008 [1]. Despite considerable advances in surgical techniques and neoadjuvant chemotherapy, the survival rate of cervical cancer is still not remarkably improved. Platinum-based anticancer agents, represented by cisplatin, have therapeutic properties for patients with cervical cancer; however, toxicities, including myelosuppression, leukopenia, ototoxicity, neurotoxicity, and nephrotoxicity [2,3], may limit their long-term use. Therefore, it is required to develop new drugs with a more specific effect and low toxicity.

Natural products have been shown to be excellent and reliable sources for the pharmaceutical development of anticancer drugs [4]. Chonglou (Rhizoma Paridis Chonglou) is the root of Paris polyphylla. Phytochemical and pharmacological studies suggest that Chonglou has a wide range

\footnotetext{
*Correspondence: 1411833615@qq.com

'Equal contributors

${ }^{2}$ Department of Pathogen Biology and Immunology, Xi'an Medical University, Xi'an, Shaanxi 710021, People's Republic of China

Full list of author information is available at the end of the article
}

of medicinal activities, including anticancer, immunoregulatory, and cardiovascular effects [5]. It has been applied in the treatment of malignant lymphomas, lung cancer, nasopharyngeal carcinoma, brain tumors, and digestive system carcinomas. Polyphyllin and extracts from Chonglou show good antitumor effects in vitro, through inducing apoptosis, affecting cell cycle distribution, inhibiting angiogenesis, and regulating the immune function $[6,7]$.

In the current study, we investigated the mechanism underlying the cytotoxic effects of a kind of steroidal saponins from Chonglou (Rhizoma Paridis Chonglou), namely, Paris saponin VII (PS VII), and its antitumor properties on Hela cell lines. The results indicated that PS VII inhibited the growth of the cell effectively. It upregulated cleaved caspase-3, cleaved caspase-9, and Bax expression in Hela cells. These preclinical studies indicated that PS VII may have potentials in the treatment of cervical cancer.

\section{Methods \\ Chemicals and reagents}

3-(4,5-Dimethylthiazol-2-yl)-2,5-diphenyltetrazolium bromide (MTT), Hoechst 33342, and propidium iodide (PI) were 
purchased from Sigma (St Louis, MO, USA). Z-VAD-FMK was from Beyotime Institute of Biotechnology (Jiangsu, China). Anti-cleaved caspase-3, cleaved caspase-9, Bcl-2, and Bax antibodies were obtained from Cell Signaling (Beverly, MA, USA). Anti- $\beta$-actin antibodies were obtained from Santa Cruz Biotechnology (Santa Cruz, CA, USA). PS VII (Figure 1) with a purity of $>98 \%$ was purchased from PureOne Biotechnology (Shanghai, China).

\section{Cell culture}

Hela, a human cervical cancer cell line, was obtained from the American Type Culture Collection (ATCC; Manassas, VA, USA) and maintained in DMEM medium supplemented with $10 \%$ fetal bovine serum, $100 \mathrm{U} / \mathrm{ml}$ penicillin, and $100 \mathrm{U} / \mathrm{ml}$ streptomycin. The cells were maintained in a humidified atmosphere at $37^{\circ} \mathrm{C}$ in $5 \% \mathrm{CO}_{2}$.

\section{Cell proliferation assays}

Cell viability was determined by MTT and 5-ethynyl-2'deoxyuridine (EdU) assays. The Hela cells were seeded at a density of $2 \times 10^{4}$ cells/well in 96-well plates full of medium containing PS VII at various concentrations (1, $3,10,30$, and $100 \mu \mathrm{M})$. After 24-h treatment, $20 \mu \mathrm{l}$ of MTT solution $(0.5 \mathrm{mg} / \mathrm{ml})$ was added into each well and the mixture was incubated at $37^{\circ} \mathrm{C}$ for $4 \mathrm{~h}$. The cells were then washed thrice with phosphate-buffered saline (PBS), and the formazan was resuspended in $150 \mu \mathrm{l}$ DMSO. Absorbance was measured at $490 \mathrm{~nm}$ by using a Bio-Rad ELISA reader (Hercules, CA, USA). Half maximal inhibitory concentrations $\left(\mathrm{IC}_{50}\right)$ of PS VII were determined by curve fitting analyses using Prism software (GraphPad Software, San Diego, CA, USA). For EdU assay, Hela cells $\left(1 \times 10^{5}\right.$ cells/well $)$ were seeded in 24 -well plates. After culture in a serum-free medium for $24 \mathrm{~h}$, various concentrations of PS VII $(0.8,1.6$, and $2.4 \mu \mathrm{M})$ were added and the cells were kept for another $24 \mathrm{~h}$. Cell viability was determined using an EdU assay kit. Stained sections were examined under a microscope (Nikon, Tokyo, Japan). All experiments were repeated independently thrice.

\section{Flow cytometric assays for annexin $\mathrm{V}$}

Hela cells were plated at a density of $5 \times 10^{6}$ per $10-\mathrm{cm}^{2}$ dish and cultured with different concentrations of PS VII

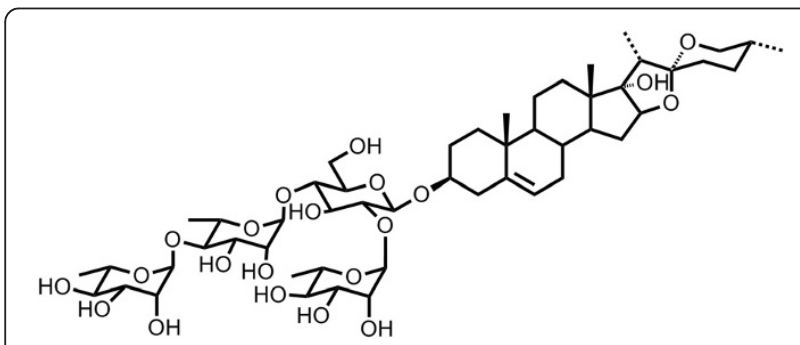

Figure 1 The structure of Paris saponin VII (PS VII). for $24 \mathrm{~h}$. A total of $1 \times 10^{6}$ to $3 \times 10^{6}$ cells were washed with ice-cold PBS and resuspended in $1 \times$ binding buffer [10 mM HEPES/NaOH (pH 7.4), 140 mM NaCl, $2.5 \mathrm{mM}$ $\mathrm{CaCl}_{2}$ ] at a concentration of $1 \times 10^{6}$ cells $/ \mathrm{ml}$. Five microliters of annexin V-fluorescein isothiocyanate (FITC) solution $(25 \mu \mathrm{g} / \mathrm{ml})$ and $5 \mu \mathrm{l}$ of dissolved PI $(250 \mu \mathrm{g} / \mathrm{ml})$ were added to $100 \mu \mathrm{l}$ of the cell suspensions. The cells were then gently vortexed and incubated at room temperature in the dark for $15 \mathrm{~min}$. Then, $400 \mu \mathrm{l}$ of ice-cold binding buffer was added and mixed gently before the cell preparations were examined by flow cytometry (FACSCalibur, Becton Dickinson, San Jose, CA, USA).

\section{Caspase-3 activity}

Caspase-3 activity in Hela cells was detected using the Caspase-3 Activity Assay Kit (Beyotime Institute of Biotechnology, Jiangsu, China). The assay is based on the hydrolysis of the peptide substrate acetyl-Asp-Glu-Val-Asp $p$-nitroanilide (Ac-DEVD-pNA) by caspase-3, resulting in the release of a pNA moiety. Absorbance values were measured at $405 \mathrm{~nm}$. Results were adjusted to the total protein content, and activity was expressed as nanomoles of pNA per milligram of total protein.

\section{Western blot analysis}

Hela cells were incubated with $0.8,1.6$, or $2.4 \mu \mathrm{M}$ of PS VII for $24 \mathrm{~h}$. The cells were then harvested and resuspended in lysis buffer (Beyotime Institute of Biotechnology, Jiangsu, China, plus the protease inhibitors leupeptin $10 \mu \mathrm{g} / \mathrm{ml}$, aprotinin $10 \mu \mathrm{g} / \mathrm{ml}$, and PMSF $0.1 \mathrm{mmol} / \mathrm{l}$ ). Protein lysates $(30 \mu \mathrm{g})$ were electrophoresed on $15 \%$ SDS polyacrylamide gels and transferred to nitrocellulose membranes (Pall Corporation, Port Washington, NY, USA) and blocked with Tris-buffered saline (TBS) buffer containing $0.05 \%$ Tween-20 and 5\% nonfat milk for $2 \mathrm{~h}$ at room temperature. The membranes were then incubated overnight at $4{ }^{\circ} \mathrm{C}$ with various primary antibodies, followed by HRP-conjugated secondary antibodies. After washing the membranes thrice for 10 min in TBS buffer containing 0.05\% Tween-20, the immunoreactive bands were detected using the Immobilon Western HRP Substrate (Millipore, Billerica, MA, USA). The experiment was repeated independently three times.

\section{Statistical analysis}

Data were expressed as mean \pm standard deviation (SD). Statistical analyses were done by using the one-way ANOVA test and Fisher's least significant difference (LSD) $t$ test to compare the different groups. Probability ( $P$ value) of less than 0.05 was considered to be statistically significant. 


\section{Results}

PS VII inhibited the cell growth of Hela cells

The viability of Hela cells treated with PS VII at different concentrations $(1,3,10,30$, and $100 \mu \mathrm{M})$ for $24 \mathrm{~h}$ was determined by MTT assay. As shown in Figure 2a, PS VII decreased the cell viability rate in a concentrationdependent manner. In comparison to the control groups, treatment with PS VII at the concentrations of 3 and $10 \mu \mathrm{M}$ decreased the survival rate of Hela cells to $51.16 \% \pm 0.58 \%$ and $14.57 \% \pm 0.24 \%$, while at the concentrations of 50 and $100 \mu \mathrm{M}$, PS VII significantly $(P<0.01)$ reduced the viability rate of Hela cells to $6.63 \% \pm 0.26 \%$ and $3.45 \% \pm 0.13 \%$. The $\mathrm{IC}_{50}$ value showed $2.62 \pm 0.11 \mu \mathrm{M}$ in Hela cells. To investigate whether this effect was selective, a normal cervical epithelial cell line, End1/E6E7, was treated with various concentrations $(1,3,10,30$, and $100 \mu \mathrm{M})$ of PS VII for $24 \mathrm{~h}$. The results show that PS VII had no obvious growth-inhibiting effect on End1/E6E7, even at the highest concentration of $100 \mu \mathrm{M}$ (Figure 2b). Based on the $\mathrm{IC}_{50}$ value, in the following steps, PS VII at the concentrations of $0.8,1.6$, and $2.4 \mu \mathrm{M}$ was chosen to treat Hela cells. Results of EdU assay (Figure 2c) also showed that PS VII exhibited an obvious growthinhibiting effect on Hela cells.

\section{PS VII induced cell apoptosis in Hela cells}

To investigate whether the growth inhibition of PS VII was caused by apoptosis, annexin V-FITC/PI assay was used. The percentage of apoptotic cells (Q2+Q4) in Hela cells was $3.77 \% \pm 0.91 \%$. When exposed to $0.8,1.6$, and $2.4 \mu \mathrm{M}$ of PS VII for $24 \mathrm{~h}$, the percentage increased to $10.50 \% \pm 2.12 \%, 17.37 \% \pm 1.86 \%$, and $38.60 \% \pm 5.34 \%$, respectively (Figure 3a). The activity of caspase-3 was also measured. As shown in Figure 3b, obvious activation of caspase-3 was observed in Hela cells treated with PS VII, which seemed to be in a concentrationdependent manner, whereas low caspase- 3 activity was detected in the control group. The decrease activity of caspase- 3 in the cells treated with PS VII was significantly blocked by pretreatment of a general caspase inhibitor, Z-VAD-FMK.

\section{PS VII acted on the intrinsic apoptotic pathway}

To search for the indication of mechanisms involved in apoptosis, the expression of cleaved caspase-3, caspase-8, and caspase- 9 was evaluated. Compared with that in control cells, the expression of caspase- 3 and caspase- 9 significantly increased in Hela cells (Figure 4) while caspase-8 had no significant change (data not shown) after being treated with $0.8,1.6$, and $2.4 \mu \mathrm{M}$ of PS VII for $24 \mathrm{~h}$. In

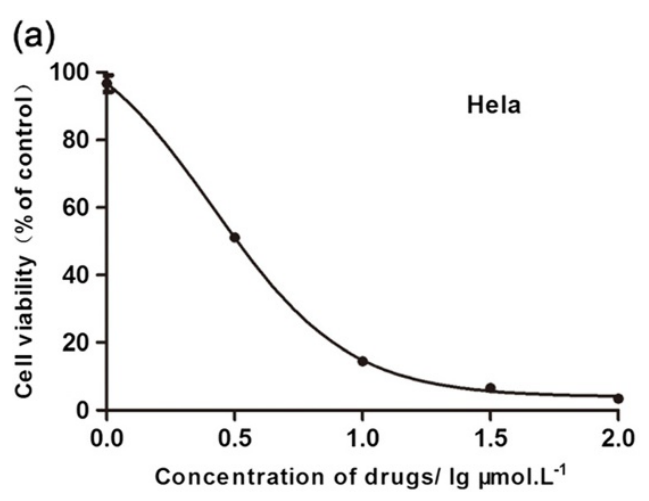

(b)

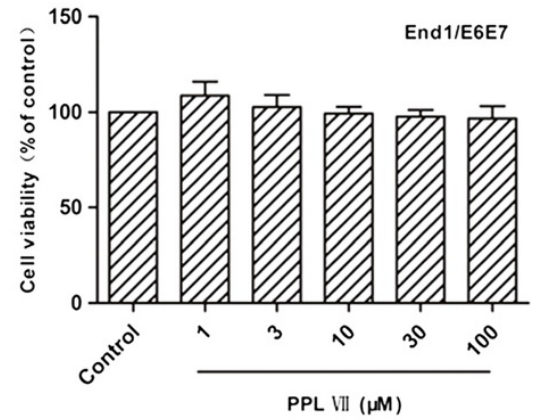

(c)
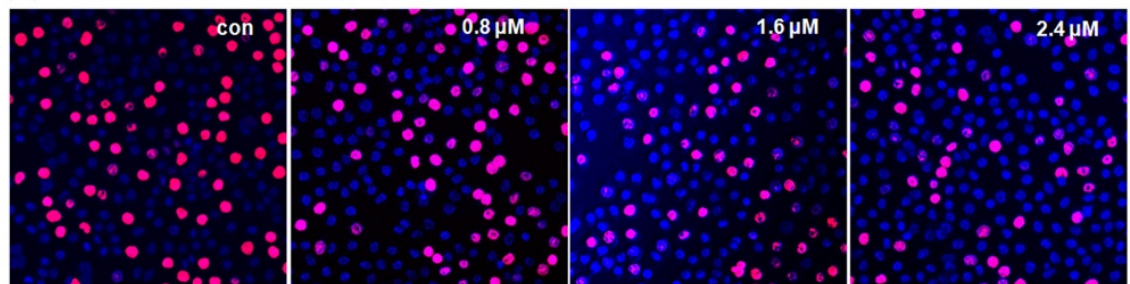

Figure 2 The effect of PS VII treatment on the growth of Hela and End1/E6E7 cell lines. (a) The effect of PS VII at the concentrations of 1, $3,10,30$, and $100 \mu \mathrm{M}$ on Hela cells. Common logarithm values of the concentrations were used as the $X$-axis. $\operatorname{Lg} 1=0.0, \operatorname{Lg} 3=0.5, \operatorname{Lg} 10=1.0$, $\operatorname{Lg} 30=1.5$, and $\operatorname{Lg} 100=2.0$. (b) The effect of PS VII at the concentrations of 1, 3, 10, 30, and $100 \mu M$ on the normal cervical epithelial cell line End1/E6E7. (c) The effect of PS VII at the concentrations of $0.8,1.6$, and $2.4 \mu \mathrm{M}$ on Hela cells. Cell proliferation of Hela cells was evaluated by EdU assays. Red staining showed proliferative cells. Sections were counterstained with Hoechst (blue) to identify the orientation of nuclei (original magnification, $\times 200)$. 
(a)

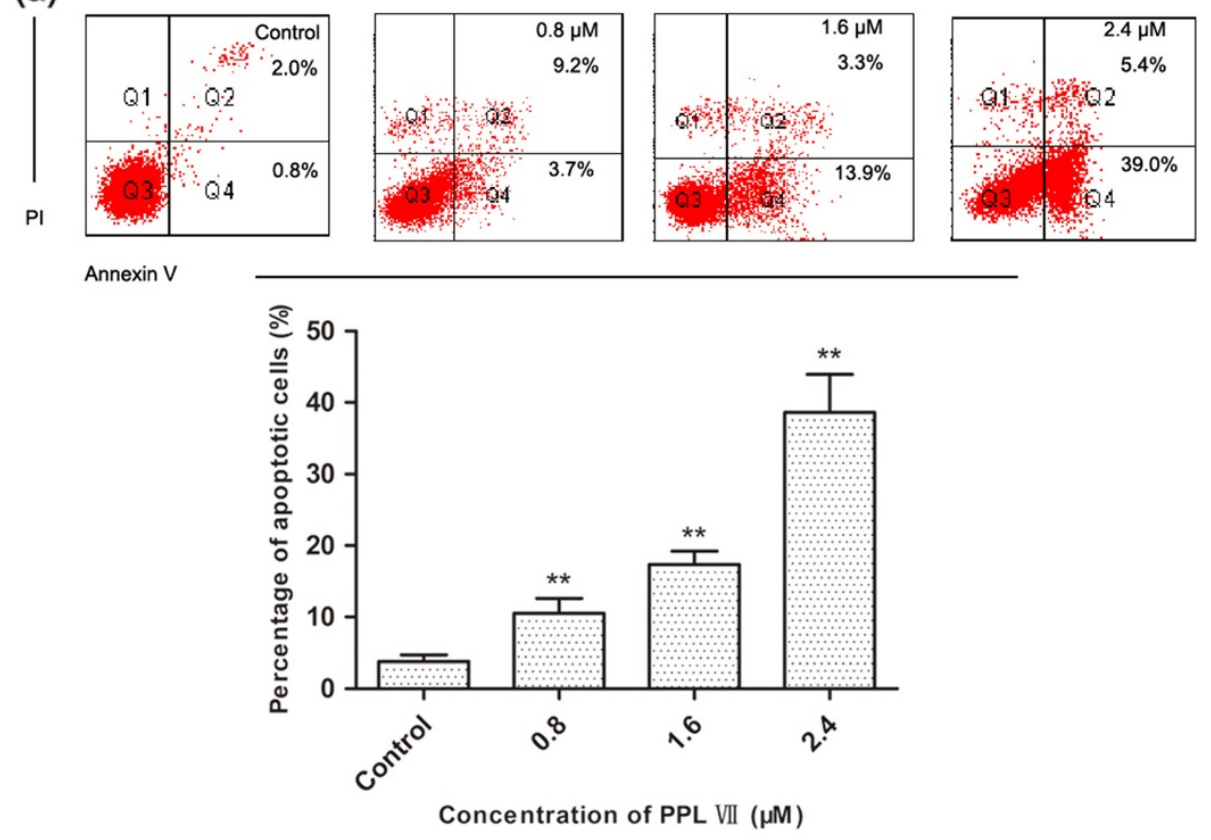

(b)

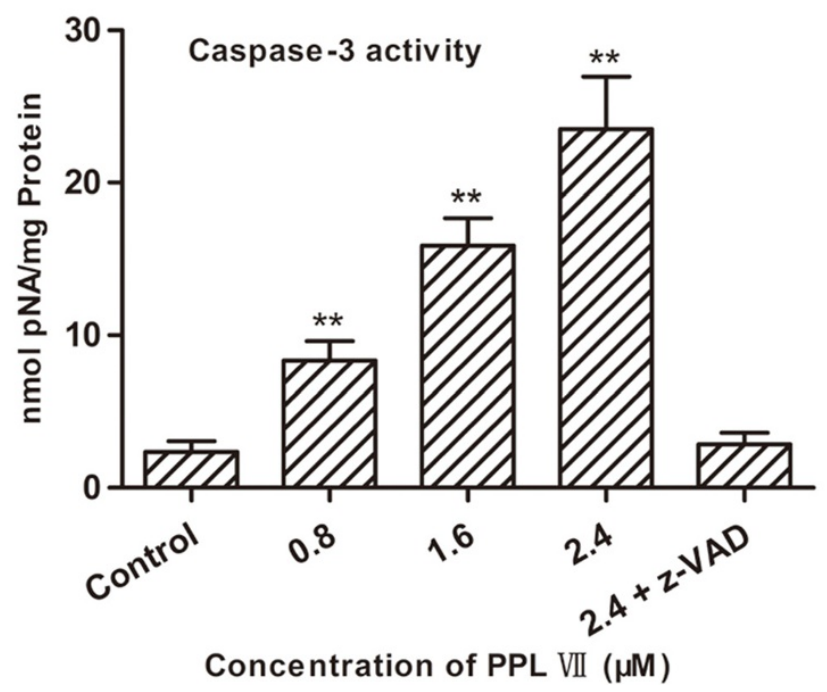

Figure 3 The effect of PS VII treatment on the apoptosis of Hela cells. (a) Annexin V analysis of Hela cells treated with PS VII at the concentrations of $0.8,1.6$, and $2.4 \mu \mathrm{M}$ for $24 \mathrm{~h}$. PS VII treatment increased the percentages of annexin $\mathrm{V}+/ \mathrm{Pl}$ - (right lower quadrant) and annexin $\mathrm{V}+/ \mathrm{PI}+(\mathrm{right}$ upper quadrant) cells. (b) Effect of PS VII on the caspase-3 activity of Hela cells. Data were the mean \pm SD of three separate experiments. ${ }^{* *} P<0.01$ vs. control.

parallel to the alterations, Bcl-2 expression decreased while Bax expression increased. Furthermore, the decrease in the levels of caspase- 3 and caspase- 9 in the cells treated with PS VII was significantly blocked by pretreatment of a general caspase inhibitor, Z-VAD-FMK (Figure 5). These data suggested that PS VII induced cell apoptosis through an intrinsic pathway depending on caspase activation.

\section{Discussion}

Chonglou (Rhizoma Paridis Chonglou) has been traditionally used for the treatment of microbial infection, hemorrhage, menometrorrhagia, and venomous poison [8-11]. The main bioactive ingredients of Chonglou are the steroidal saponins. Phytochemical and pharmacological studies have further revealed a novel therapeutic role as an anticancer agent for these steroid saponins [12]. However, evidence-based researches into the mechanism underlying the cytotoxic effects of steroidal saponins are still undefined.

In the current study, we found that PS VII, a kind of steroidal saponins from Chonglou, could inhibit the growth of Hela cells in a concentration-dependent manner. 


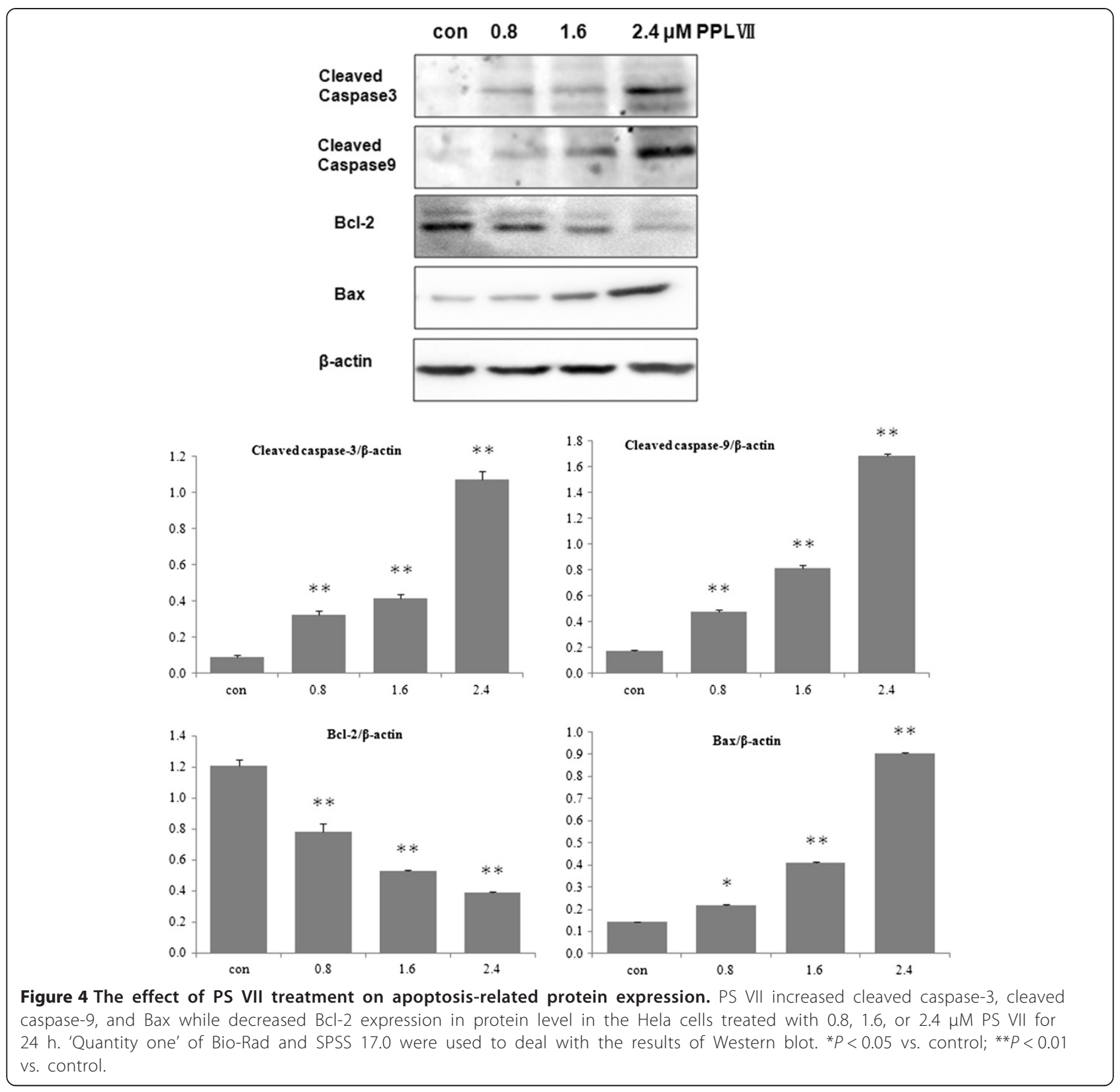

We then attempted to investigate whether the growthinhibiting effect of PS VII was caused by apoptosis.

Apoptosis, which is characterized by membrane blebbing, shrinkage of the cytoplasm and nucleus, and DNA fragmentation [13], helps to keep tissue homeostasis by eliminating potentially deleterious cells. Deregulated apoptotic cell death would lead to diseases such as cancer. In cancer cells, the incidence of apoptosis and the rate of cell proliferation are uncontrolled, which would cause tumor invasion. Therefore, it will be a reasonable way to induce cancer cells to undergo apoptosis by various anticancer agents.
Results of flow cytometric analysis showed that PS VII increased the apoptosis of Hela cells in a concentrationdependent manner.

Mammalian cells undergo apoptosis mainly through two ways: the death receptor-mediated or extrinsic pathway and the mitochondrial-mediated or intrinsic pathway [14]. Caspases, a family of cysteine proteases, are central regulators of apoptosis. Caspase- 8 is involved in the extrinsic and caspase- 9 in the intrinsic pathway. After activation, they would cleave and activate downstream effectors such as caspase-3, which subsequently cleave cytoskeletal and nuclear proteins $[15,16]$. Results of caspase-3 activity 

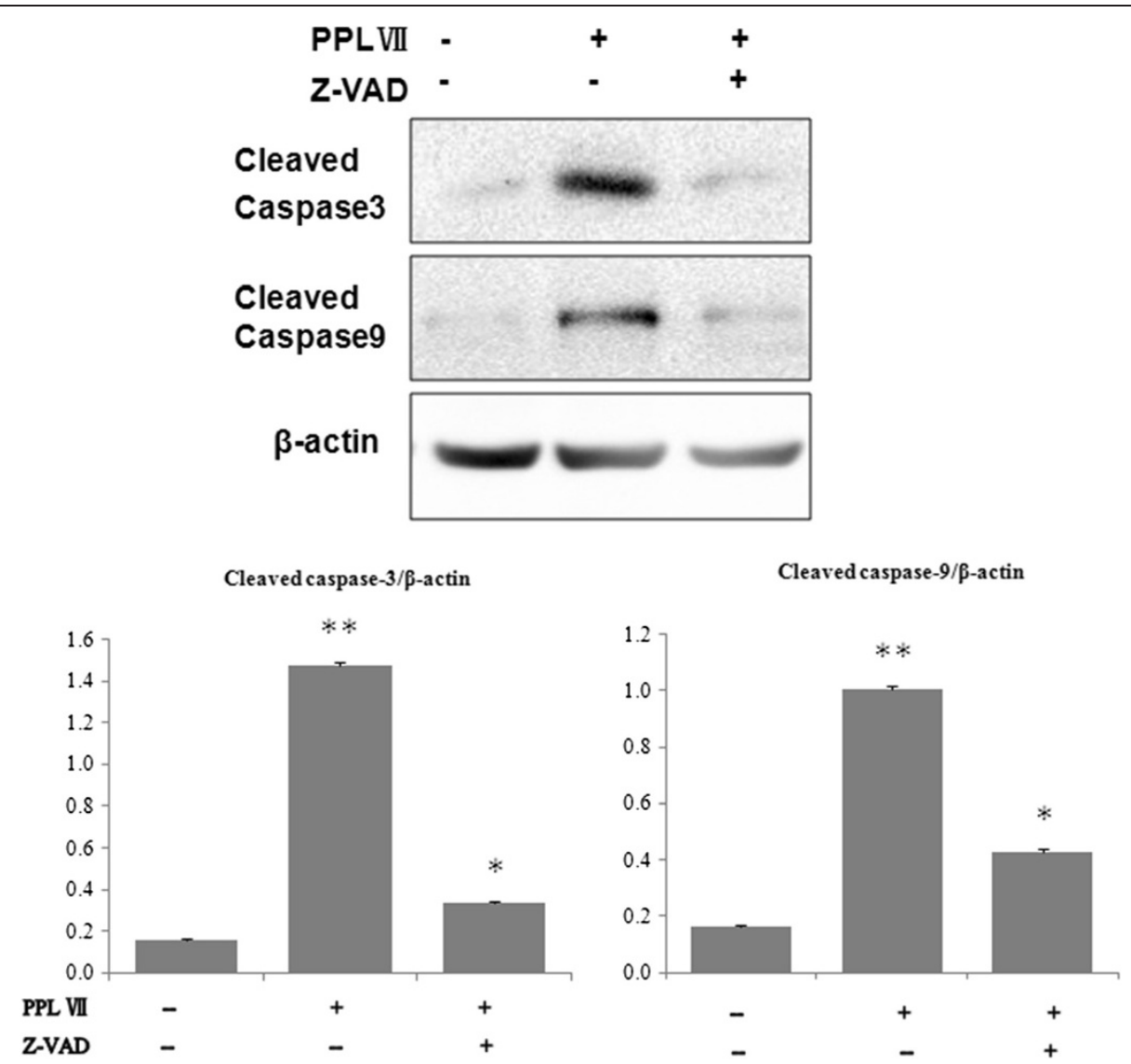

Figure 5 Activation of caspase-3 and caspase-9 after treatment with PS VII. Cell lysates were prepared after treatment with drugs for $24 \mathrm{~h}$ and then analyzed by Western blot with caspase-3 or caspase- 9 antibody. The protein level of cleaved caspase-3 and caspase- 9 was increased by PS VII treatment. However, the activation of caspase-3 and caspase-9 was minimized after pretreatment of a pan-caspase inhibitor (Z-VAD-FMK). 'Quantity one' of Bio-Rad and SPSS 17.0 were used to deal with the results of Western blot. ${ }^{*} P<0.05$ vs. control; ${ }^{*} P<0.01$ vs. control.

assay showed that PS VII treatments led to increased caspase-3 activity in Hela cells. And these effects seemed to be concentration dependent. Western blot analysis demonstrated that PS VII treatments caused increased cleaved caspase- 3 and caspase- 9 expression, but had no significant effect on cleaved caspase- 8 expression. The cleavage of caspases was prevented by pretreatment of Hela cells with a pan-caspase inhibitor, Z-VAD-FMK. These findings suggest that PS VII induced the apoptosis of Hela cells through an intrinsic way involving caspase activation.

This was proved by decreased Bcl-2 expression and increased Bax expression. The Bcl-2 protein family, which plays an important role in the intrinsic pathway, is divided into two functional subfamilies: pro-apoptotic proteins (Bax and $\mathrm{Bid}$ ) and anti-apoptotic proteins (Bcl-2 and $\mathrm{Bcl}-\mathrm{xL}$ ). The ratio of $\mathrm{Bax} / \mathrm{Bcl}-2$ appears to be a critical determinant of a cell's threshold for undergoing apoptosis. Results obtained above were from in vitro experiments. In the next step, we will assess the effect of PS VII in vivo and find the possible mechanisms by using xenograft models.

\section{Conclusions}

In brief, the results reported herein demonstrated that PS VII inhibited the growth and induced the apoptosis of Hela cells effectively. One of the possible mechanisms involved is that PS VII triggered cell apoptosis via an intrinsic pathway depending on caspase activation. The precise signaling pathway remains to be further investigated. However, these data may provide an approach to treat cervical cancer.

\section{Competing interests}

The authors declare that they have no competing interests.

\section{Authors' contributions}

WJZ and DZ participated in the design of the study and performed the statistical analysis. XM, DNW, and FL carried out the study and together with ZYL collected important background information. WJZ drafted the manuscript. All authors read and approved the final manuscript.

\section{Acknowledgements}

This investigation was supported by Grant No. 2014JQ4152 from the Technology Gallery of Shaanxi Province and Grant No. 2012D45 from the Department of Public Health of Shaanxi Province. 


\section{Author details}

'Maternal and Child Health Hospital of Xi'an, Xi'an, Shaanxi 710003, People's Republic of China. ${ }^{2}$ Department of Pathogen Biology and Immunology, Xi'an Medical University, Xi'an, Shaanxi 710021, People's Republic of China.

Received: 16 May 2014 Accepted: 21 July 2014

Published: 15 August 2014

\section{References}

1. Ferlay J, Shin HR, Bray F, Forman D, Mathers C, Parkin DM: Estimates of worldwide burden of cancer in 2008: GLOBOCAN 2008. Int I Cancer 2010, 127:2893-2917.

2. Alderden RA, Hall MD, Hambley TW: The discovery and development of cisplatin. J Chem Educ 2006, 83:728-734.

3. Boulikas T: Molecular mechanisms of cisplatin and its liposomally encapsulated form, Lipoplati ${ }^{\mathrm{TM}}$. Lipoplatin ${ }^{\mathrm{TM}}$ as a chemotherapy and antiangiogenesis drug. Cancer Ther 2007, 5:351-376.

4. Mann J: Natural products in cancer chemotherapy: past, present and future. Nat Rev Cancer 2002, 2:143-148.

5. Zhao BS, Zhu YD, Ma Y, Gui HS, Xu DH: Research progress in traditional Chinese medicine polyphylla. Zhong Guo Shi Yan Fang Ji Xue Za Zhi 2011, 17:267.

6. Wu S, Wu W, Zheng YL: Simultaneous determination of four steroidal saponins compounds in Paris ployphylla by high performance liquid chromatography reversed-phase. Shi Zhen Guo Yi Guo Yao 2007, 18:1896-1897.

7. Sun J, Liu BR, Hu WJ, Yu LX, Qian XP: In vitro anticancer activity of aqueous extracts and ethanol extracts of fifteen traditional Chinese medicines on human digestive tumor cell lines. Phytother Res 2007, 21:1102.

8. Vassilopoulos Y: Paris polyphylla. A Literary Favour to World Culture. Newsfinder. 2008 [http://www.newsfinder.org/search/results/ $1 \mathrm{~d} 7753845881424 \mathrm{bd} 8 \mathrm{a} 051443 \mathrm{ab} 7836 \mathrm{~b} / \mathrm{s}$

9. Wang Q, Cheng YB: The bacteriostasis and hermostasis functions of Paris polyphylla Smith var. Chinensis (French) Hera. J of China Pharma Univer 1989, 20:251-253.

10. Harborne JB: Saponins used in traditional and modern medicine and saponins used in food and agriculture. Phytochem 1997, 46:1301-1303.

11. XC ZX: The study and application of Paris plant. J of Chinese Herbal Tech 2000, 7:346-347.

12. Wang H, Zhai Z, Li N, Jin H, Chen J, Yuan S, Wang L, Zhang J, Li Y, Yun J, Fan J, Yi J, Ling R: Steroidal saponin of Trillium tschonoskii. Reverses multidrug resistance of hepatocellular carcinoma. Phytomed 2013, 20:985-991.

13. Kerr JF, Wyllie AH, Currie AR: Apoptosis: a basic biological phenomenon with wide range implications in tissue kinetics. Br J Cancer 1972, 26:239-257.

14. Kang $\mathrm{MH}$, Reynolds $\mathrm{CP}: \mathrm{BCl}-2$ inhibitors: targeting mitochondrial apoptotic pathways in cancer therapy. Clin Cancer Res 2009, 15:1126-1132.

15. Nangia-Makker P, Nakahara S, Hogan V, Raz A: Galectin-3 in apoptosis, a novel therapeutic target. J Bioenerg Biomembr 2007, 39:79-84.

16. Khan N, Afaq F, Mukhtar H: Apoptosis by dietary factors: the suicide solution for delaying cancer growth. Carcinogenesis 2007, 28:233-239.

doi:10.1186/2047-783X-19-41

Cite this article as: Zhang et al:: Paris saponin VII suppressed the growth of human cervical cancer Hela cells. European Journal of Medical Research 2014 19:41.

\section{Submit your next manuscript to BioMed Central and take full advantage of:}

- Convenient online submission

- Thorough peer review

- No space constraints or color figure charges

- Immediate publication on acceptance

- Inclusion in PubMed, CAS, Scopus and Google Scholar

- Research which is freely available for redistribution 